\title{
Relative Toxicity of Some Newer Insecticides against Mustard aphid, Lipaphis erysimi (Kalt.) on Gobhi sarson
}

\author{
N. Ramana*, R.S. Bandral and Zahid Abass wazir
}

Division of Entomology, Faculty of Agriculture, Sher-e-Kashmir University of Agricultural

Sciences and Technology, Chatha, Jammu-180 009 (J\&K), India

*Corresponding author

\section{A B S T R A C T}

The Relative toxicity of methyl-o-demeton, spinosad, acetamiprid, chlorfenapyr and

Keywords

Relative toxicity,

Insecticides, Direct spray,

Leaf dip, Lipaphis

erysimi

Article Info

Accepted:

07 October 2018

Available Online:

10 November 2018

fipronil were evaluated against mustard aphid, Lipaphis erysimi (Kalt.) on Gobhi sarson var. DGS-1 during 2017-18. The $\mathrm{LC}_{50}$ values of insecticides viz., methyl-o-demeton, spinosad, acetamiprid, chlorfenapyr and fipronil were 4.772, 55.406, 4.657, 5.554 and 15.107 ppm, respectively by direct spray method indicating that acetamiprid exhibited greater toxicity among the tested insecticides. However, by leaf dip method, the LC50 values of insecticides were $6.034,9.142,6.487,5.429$ and $67.505 \mathrm{ppm}$, respectively, which indicated that chlorfenapyr, was the most toxic among the insecticides tested. The relative toxicity of acetamiprid, methyl-o-demeton, chlorfenapyr and fipronil over spinosad were found to be $11.89,11.61,9.97$ and 3.66 times more effective, respectively. Whereas, in leaf dip method of bioassay the relative toxicity of chlorfenapyr, methyl-o-demeton, acetamiprid and spinosad over fipronil were found to be $12.4311 .18,10.40$ and 7.38 times more effective, respectively.

\section{Introduction}

Oilseed crops are generally one of the most important crops in the world. Rapeseedmustard is the major oilseed crop grown in various states of the country. This crop is the major source of income especially to the marginal and small farmers in rainfed areas. Because of its low water requirement (80-240 $\mathrm{mm}$ ), rapeseed-mustard crop fits well in the rainfed cropping system. Rapeseed-mustard crop (Brassica sps.) is grown both in subtropical and temperate countries and it is the third most important oilseed crop in the world after soybean (Glycine max) and palm oil, Elaeis guineensis (Jacq.). The share of oilseeds is $14.1 \%$ out of the total cropped area in India, Rapeseed-mustard accounts for $3 \%$ of it (Kapila et al., 2012). In India, this crop is grown in diverse agro-climatic conditions ranging from north-eastern/north-western hills to down south under irrigated/rainfed, timely/late sown and mixed cropping. It is cultivated in 5.76 million hectares with an annual production of 6.82 million tones and average productivity of $1184 \mathrm{~kg} / \mathrm{ha}$ which contributes $28.3 \%$ and $19.8 \%$ in world acreage and production (Anon., 2016a). India has the largest area and highest production of mustard. Currently, Rajasthan is the top 
mustard producing state of India with an area of 2.55 million ha and production of 3.27 million tonnes, followed by Haryana and Madhya Pradesh (Anon., 2016b).

Aphids are important group of insects with worldwide distribution and a truly interesting group of herbivorous insects and can affect plants directly or indirectly by feeding on the plant sap. Mustard aphid, L. erysimi (Kalt.) have been reported as a major constraint responsible for this low yield level, which causes average yield losses ranging 27.3$94.5 \%$ in Indian mustard due to aphids (Singh et al., 2000; Malik et al., 2003). This species causes damage to plants in two ways, initially by sucking the plant sap and subsequently secreting a sticky substance (honeydew) on which 'sooty mold' develops, which interferes with photosynthesis (Raboudi et al., 2002). Increase in aphid population beyond 25 aphids $/ 10 \mathrm{~cm}$ terminal shoot/plant reduces seed yield by $1.5 \mathrm{~kg} / \mathrm{ha}$ (Singh et al., 1983). It has attained the key pest status in rapeseedmustard because of its prolific multiplication and severe damage, resulting in curling of the leaf, stunting and drying up of the plants (Rana et al., 2007).

The major problems associated with chemical control of mustard aphid are the development of insecticidal resistance, resurgence, pest outbreak etc., against most of the commonly used broad spectrum insecticides in the field. This has obliged the use of new eco-friendly, ecologically acceptable insecticides against mustard aphids and resistance build up problems against these traditional insecticides can be easily breakdown by using the newer group of molecules. In this context, the present study was conducted for assessing the relative toxicity of four newer insecticides along with a conventional insecticide methylo-demeton in laboratory conditions against mustard aphid. Therefore, efforts were made to determine the relative toxicity and economics of some newer insecticides for the management of mustard aphid on Indian mustard in Jammu and Kashmir.

\section{Materials and Methods}

Studies on relative toxicity assessment of selected insecticides against mustard aphid, $L$. erysimi were conducted in the laboratory of Division of Entomology and Experimental Farm of Division of Entomology, SKUASTJammu. Mustard aphids were reared on potted Gobhi sarson, Brassica napus L. variety (DSH-1) plants. Mustard seeds were also sown in an area of $5 \mathrm{~m}^{2}$ in Technology Park of SKUAST-Jammu for availing the leaf material. Aphids were collected from the sown mustard plants and released on these potted plants. Generations of these aphids on the potted plants were used for bioassay studies. Commercial formulations of methyl-odemeton 35 EC (Metasystox®, United Phosphorous Limited), acetamiprid 20 SP (Pride®, Indo-Gulf Group), spinosad 45 SC (Tracer®, Dow Agro Sciences. India Pvt. Ltd.), fipronil 5 SC (Reagent ${ }^{\circledR}$, Bayer Crop Science Limited) and chlorfenapyr (Interprid®, BASF India Limited.) were obtained from the respective manufacturers. Desired concentrations of these were prepared by dilution with water. Six concentrations of each insecticide including control were screened in the laboratory against the neonate mustard aphids $L$. erysimi to obtain the $\log$ concentration- probit mortality curve. Each treatment was replicated thrice. The relative toxicity of the insecticides was calculated based on the percentage of aphid mortality after $24 \mathrm{hrs}$ of treatment.

\section{Bioassay studies}

\section{Direct spray method}

Leaf samples of untreated Gobhi sarson, Brassica napus L. (variety: DSH-1) crop were 
brought to the laboratory from already sown mustard field in Technology Park of SKUAST-Jammu. These leaves were washed with tap water. After washing, leaf discs of 9 $\mathrm{cm}$ size were made. These leaf discs were dried for 5 minutes at room temperature. In preliminary tests reared apterous aphids were exposed to wider range of concentrations of all insecticides and on the basis of mortality recorded, a series of concentrations in narrow range were selected. Finally aphids were exposed to narrow range of concentrations of each insecticide for bioassay studies.

Twenty apterous neonate aphids of same size were released in each Petriplate by using soft camel hair brush and sprayed directly with 3 $\mathrm{ml}(1 \mathrm{ml} /$ Petriplate) of predetermined insecticidal solutions in the batches of three Petriplates by using Burkardo Computer controlled spraying apparatus at a pressure of $10-15 \mathrm{~g} / \mathrm{cm}^{2}$. For control only distilled water was used for spraying. Then the treated aphids were transferred to clean Petriplates containing fresh leaf discs (upside down) of Gobhi sarson as food. In order to maintain moisture a moist filter paper was placed in each Petriplate under the leaf disc. These petriplates were kept in B.O.D. incubator at 26 \pm 10 C. For assessment of $\mathrm{LC}_{50}$ values, mortalities were recorded after 24 hours of the treatment. The moribund aphids were also considered as dead.

\section{Leaf dip method}

To study the residual bio efficacy potential, the apterous neonate aphids were exposed to insecticidal residues on mustard leaves. The fresh uninfected untreated fully-grown Gobhi sarson leaves with petiole were brought to the laboratory and thoroughly washed with water. After washing, leaf discs of $9 \mathrm{~cm}$ Petriplate size were prepared. These leaf discs were dried for 5 minutes at room temperature. Later, these leaf discs were dipped in desired concentrations of each insecticide for 30 seconds in the $250 \mathrm{ml}$ beaker and shade dried. Then the treated leaf discs were transferred to clean Petriplates. Later, twenty apterous neonate aphids of same size were carefully released on the treated leaf by using a soft camel hair brush. Each treatment including control was replicated thrice. For control, the Gobhi sarson leaves were dipped only in water, dried and used. The Petriplates were kept in B.O. D. incubator at $26 \pm 10 \mathrm{C}$.

For assessment of LC50 values, mortalities were recorded after 24 hours of the treatment. The moribund aphids were also considered as dead. The concentrations giving the mortality ranging from 15 to 95 per cent were selected. The mortality was converted to percent mortality and corrected mortality was calculated as per Abbott`s (1925) formula.

$\%$ mortality in treatment-\%mortality in control Corrected $\%$ mortality = --------------- x 100 $100-\%$ mortality in control

The data were further subjected to probit analysis for calculating $\mathrm{LC}_{50}$ and $\mathrm{LC}_{90}$ values. The LC50 values of insecticides against aphids were expressed as parts per million (ppm). The relative toxicity values for different insecticides were calculated by using following formula.

Relative toxicity $=$

$\mathrm{LC}_{50}$ of least toxic compound.

$\mathrm{LC}_{50}$ of most toxic compound.

\section{Results and Discussion}

The perusal data of $\mathrm{LC}_{50}$ values revealed that acetamiprid $20 \mathrm{SP}$ had the maximum toxicity $\left(\mathrm{LC}_{50} 4.657 \mathrm{ppm}\right)$ against mustard aphid $L$. erysimi after 24 hours exposure in direct spray method followed by methyl-o-demeton 25 EC (4.772 ppm), chlorfenapyr $10 \mathrm{SC}$ (5.554 ppm), fipronil 5 SC (15.107 ppm) and spinosad 
(55.406 ppm). The relative toxicity of acetamiprid, methyl-o-demeton, chlorfenapyr and fipronil over spinosad were found to be 11.89, 11.61, 9.97 and 3.66 times more effective, respectively and the order of relative toxicity was in the following order: acetamiprid, (11.89) > methyl-o-demeton (11.61) > chlorfenapyr (9.97) > and fipronil (3.66) after taking the relative toxicity of the spinosad as unity. Earlier, Awasthi et al., (2013) also reported the higher toxicity of acetamiprid (87.95\%) against $L$. erysimi (Kalt.) with the $\mathrm{LC}_{50}$ value being $0.007 \mathrm{ppm}$ followed by acephate $(0.025 \mathrm{ppm})$, imidacloprid (0.036 ppm), emamectin benzoate $(0.368 \mathrm{ppm})$, indoxacarb $(0.397$ ppm) and spinosad (0.576 ppm).

Direct application of acetamiprid, methyl-odemeton, chlorfenapyr and fipronil were found to be more effective as evidenced by low $\mathrm{LC}_{50}$ values as compared to leaf dip method. The $\mathrm{LC}_{50}$ values of methyl-o-demeton, spinosad, acetamiprid, chlorfenapyr and fipronil were 4.772 ppm, 55.406, 4.657, 5.554 and 15.107 ppm, respectively indicating that acetamiprid was comparatively more toxic to mustard aphid, L. erysimi in direct spray method. Results of present study are in same line with the findings of Powar et al., (2015), they noted that acetamiprid was most toxic insecticide $(63.23 \mathrm{ppm})$ followed by imidacloprid (133.87), dimethoate (334.84) and methyl demeton (348.45 ppm).

Sharma et al., (2006) also reported that acetamiprid was the most toxic insecticide and the order of toxicity of insecticides was acetamiprid > imidacloprid > quinalphos > monocrotophos $>$ endosulfan $>$ chlorpyriphos $>$ dimethoate $>$ spinosad $>$ cypermethrin. Studies of Dhawan et al., (2009) also determined the relative toxicity of imidacloprid, acetamiprid, quinalphos, endosulfan, novaluron, thiamethoxam, triazophos, chlorpyrifos and clothianidin against cotton aphid, Aphis gossypii and the order of toxicity of insecticides was thiamethoxam > acetamiprid > novaluron > imidacloprid $>$ triazophos $=$ quinalphos $>$ endosulfan > chlorpyrifos $=$ clothianidin > ethion with $\mathrm{LC}_{50}$ values $10000,5500,1250$, 500, 250, 250, 120, 80, 80and70 ppm, respectively. Experimental results of Pandi et al., (2013) also stated that acetamiprid was most toxic insecticide than other insecticides against grubs of Cheilomenes sexmaculata and the descending order of toxicity of based on $\mathrm{LC}_{50}$ value was acetamiprid (50ppm) > thiamethoxam (60ppm) > imidacloprid (170 ppm). However studies of Devi et al., (2003) reported that methyl-demeton, dimethoate was highly toxic to Diaeretiella rapae a common parasitoid of mustard aphid L. erysimi with 50- $95 \%$ mortality under direct exposure conditions. The toxicity of neonicotinoids (acetamiprid) against L. erysimi was more pronounced than other class of insecticides due to direct toxicity as well as their avoidance behaviour as antifeedant/ repellent responses.

However leaf dip method was observed to be more effective as compared to direct spray in case of chlorfenapyr and spinosad. In leaf dip method the $\mathrm{LC}_{50}$ values of methyl-o-demeton, spinosad, acetamiprid, chlorfenapyr and fipronil were $6.034,9.142,6.487,5.429$ and 67.505 ppm shown that chlorfenapyr was comparatively more toxic and the order of relative toxicity was chlorfenapyr (12.43) > methyl-o-demeton (11.18) acetamiprid (10.40) and spinosad (7.38) after taking the relative toxicity of the fipronil as unity. In the leaf dip method, the order of toxicity of insecticides changed perceptibly. In this method chlorfenapyr was the most toxic insecticide followed by methyl-o- demeton, acetamiprid, spinosad and fipronil. In the present studies, chlorfenapyr was found to be the most potent insecticide against mustard aphid followed by methyl-o- demeton (Table 1-6). 
Table.1 Details of insecticides tested against Lipaphis erysimi

\begin{tabular}{|c|c|c|c|c|c|c|}
\hline S. No & Common name & Chemical group/ Source & Trade name & Formulation & Manufacturer & $\begin{array}{c}\text { Recommended dose } \\
(\%)\end{array}$ \\
\hline 11 & Fipronil & Phenyl Pyrazoles & Regent & $5 \mathrm{SC}$ & $\begin{array}{c}\text { Bayer Crop } \\
\text { Science Limited. }\end{array}$ & 0.005 \\
\hline 22 & Acetamiprid & Neo nicotinoids & Prize & $20 \mathrm{SP}$ & $\begin{array}{l}\text { Indo-Gulf Group, } \\
\text { India. }\end{array}$ & 0.005 \\
\hline 33 & Spinosad & Actinomycetes derivative & Tracer & $45 \mathrm{SC}$ & $\begin{array}{c}\text { Dow Agro Sciences. } \\
\text { India } \\
\text { Pvt. Ltd. }\end{array}$ & 0.030 \\
\hline 44 & Chlorfenapyr & Halogenated pyrrole & Intreprid & $10 \mathrm{SC}$ & $\begin{array}{l}\text { BASF India } \\
\text { Limited. }\end{array}$ & 0.015 \\
\hline 55 & Methyl-0-Demeton & Organo-phosphorus & Metasystox & $25 \mathrm{EC}$ & $\begin{array}{c}\text { Union Phosphorus } \\
\text { Limited, India. }\end{array}$ & 0.030 \\
\hline
\end{tabular}

Table. 2 Concentrations of insecticides used in direct spray method

\begin{tabular}{|l|l|l|}
\hline Insecticides & Method & Concentrations used (ppm) \\
\hline Acetamiprid & $\begin{array}{l}\text { Direct spray } \\
\text { Leaf dip }\end{array}$ & $\begin{array}{l}100,50,10,1,0.1,0.01 . \\
100,50,10,1,0.1,0.01 .\end{array}$ \\
\hline Spinosad & $\begin{array}{l}\text { Direct spray } \\
\text { Leaf dip }\end{array}$ & $\begin{array}{l}1000,500,100,50,10,5 . \\
1000,500,100,50,10,5 .\end{array}$ \\
\hline Chlorfenapyr & $\begin{array}{l}\text { Direct spray } \\
\text { Leaf dip }\end{array}$ & $\begin{array}{l}100,50,10,5,2.5,0.25 . \\
100,50,10,5,2.5,0.25 .\end{array}$ \\
\hline Fipronil & $\begin{array}{l}\text { Direct spray } \\
\text { Leaf dip }\end{array}$ & $\begin{array}{l}1000,500,100,10,5,1 . \\
1000,500,100,10,5,1 .\end{array}$ \\
\hline Methyl-0-demeton & $\begin{array}{l}\text { Direct spray } \\
\text { Leaf dip }\end{array}$ & $\begin{array}{l}100,50,10,5,2.5,1.25 . \\
100,50,10,5,2.5,1.25 .\end{array}$ \\
\hline
\end{tabular}


Table.3 Mortality response of insecticides against Lipaphis erysimi by direct spray method

\begin{tabular}{|c|c|c|c|c|c|c|c|c|c|}
\hline \multicolumn{2}{|c|}{ Methyl-o-demeton } & \multicolumn{2}{|c|}{ Spinosad } & \multicolumn{2}{|c|}{ Acetamiprid } & \multicolumn{2}{|c|}{ chlorfenapyr } & \multicolumn{2}{|c|}{ Fipronil } \\
\hline $\begin{array}{l}\text { Conc. } \\
\text { (ppm) }\end{array}$ & $\begin{array}{l}\text { Corrected \% } \\
\text { mortality }\end{array}$ & $\begin{array}{l}\text { Conc. } \\
\text { (ppm) }\end{array}$ & $\begin{array}{l}\text { Corrected } \\
\% \text { mortality }\end{array}$ & $\begin{array}{l}\text { Conc. } \\
\text { (ppm) }\end{array}$ & $\begin{array}{c}\text { Corrected \% } \\
\text { mortality }\end{array}$ & $\begin{array}{l}\text { Conc. } \\
\text { (ppm) }\end{array}$ & $\begin{array}{l}\text { Corrected \% } \\
\text { mortality }\end{array}$ & Conc. (ppm) & $\begin{array}{l}\text { Corrected \% } \\
\text { mortality }\end{array}$ \\
\hline 100 & 91.37 & 1000 & 89.28 & 100 & 94.54 & 100 & 85.71 & 1000 & 87.71 \\
\hline 50 & 84.48 & 500 & 78.57 & 50 & 83.63 & 50 & 76.78 & 500 & 77.19 \\
\hline 10 & 72.41 & 100 & 60.71 & 10 & 70.90 & 10 & 67.85 & 100 & 61.40 \\
\hline 5 & 55.17 & 50 & 44.64 & 5 & 56.36 & 5 & 55.35 & 10 & 56.14 \\
\hline 2.5 & 39.65 & 10 & 32.14 & 1 & 34.54 & 2.5 & 23.21 & 5 & 42.10 \\
\hline 1.25 & 17.24 & 5 & 12.50 & 0.1 & 16.36 & 0.25 & 14.28 & 1 & 19.29 \\
\hline
\end{tabular}

Data are means of three replications.

Table.4 Relative toxicity of insecticides against Lipaphis erysimi by direct spray method

\begin{tabular}{|c|c|c|c|c|c|c|c|c|c|c|c|c|}
\hline \multirow[t]{3}{*}{ Insecticide } & \multirow{2}{*}{\multicolumn{2}{|c|}{ Heterogeneity }} & \multirow[t]{3}{*}{$\begin{array}{l}\text { Regression } \\
\text { Equation }\end{array}$} & \multirow[t]{3}{*}{$\begin{array}{c}\mathrm{LC}_{50} \\
(\mathrm{ppm})\end{array}$} & \multicolumn{2}{|c|}{$\begin{array}{c}\text { Fiducial } \\
\text { limits }\end{array}$} & \multirow[t]{3}{*}{$\begin{array}{c}\text { Slope } \pm \text { SE } \\
\text { (b) }\end{array}$} & \multirow[t]{3}{*}{$\begin{array}{l}\text { Relative } \\
\text { Toxicity }\end{array}$} & \multirow[t]{3}{*}{$\begin{array}{l}\text { Order of } \\
\text { Toxicity }\end{array}$} & \multirow[t]{3}{*}{$\begin{array}{l}\mathrm{LC}_{90} \\
(\mathrm{ppm})\end{array}$} & \multicolumn{2}{|c|}{ Fiducial limits } \\
\hline & & & & & Lower & Upper & & & & & Lower & Upper \\
\hline & $\chi^{2}$ & d.f & & & & & & & & & & \\
\hline $\begin{array}{l}\text { Methyl-0- } \\
\text { demeton }\end{array}$ & 5.27 & 4 & $Y=0.833+1.133 X$ & 4.772 & 3.565 & 6.389 & $1.133 \pm 0.120$ & 11.61 & 2 & 64.583 & 48.240 & 36.461 \\
\hline Spinosad & 3.55 & 4 & $Y=0.656+0.916 X$ & 55.406 & 38.542 & 79.648 & $0.916 \pm 0.096$ & 1 & 5 & 1390.023 & 966.948 & 998.208 \\
\hline Acetamiprid & 6.45 & 4 & $Y=1.143+1.051 X$ & 4.657 & 3.413 & 6.355 & $1.051 \pm 0.113$ & 11.89 & 1 & 77.070 & 56.478 & 05.170 \\
\hline Chlorfenapyr & 9.47 & 4 & $Y=1.752+0.867 X$ & 5.554 & 3.813 & 8.090 & $0.867 \pm 0.093$ & 9.97 & 3 & 166.889 & 114.568 & 243.102 \\
\hline Fipronil & 5.72 & 4 & $Y=2.650+0.560 X$ & 15.107 & 8.500 & 26.851 & $0.560 \pm 0.068$ & 3.66 & 4 & 2936.680 & 1652.297 & 5219.455 \\
\hline
\end{tabular}


Table.5 Mortality response of insecticides against L. erysimi by leaf dip method

\begin{tabular}{|c|c|c|c|c|c|c|c|c|c|}
\hline \multicolumn{2}{|c|}{ Methyl-o-demeton } & \multicolumn{2}{|c|}{ Spinosad } & \multicolumn{2}{|c|}{ Acetamiprid } & \multicolumn{2}{|c|}{ Chlorfenapyr } & \multicolumn{2}{|l|}{ Fipronil } \\
\hline $\begin{array}{l}\text { Conc. } \\
\text { (ppm) }\end{array}$ & $\begin{array}{l}\text { Corrected \% } \\
\text { mortality }\end{array}$ & $\begin{array}{l}\text { Conc. } \\
\text { (ppm) }\end{array}$ & $\begin{array}{l}\text { Corrected \% } \\
\text { mortality }\end{array}$ & $\begin{array}{l}\text { Conc. } \\
\text { (ppm) }\end{array}$ & $\begin{array}{l}\text { Corrected\% } \\
\text { mortality }\end{array}$ & $\begin{array}{l}\text { Conc. } \\
\text { (ppm) }\end{array}$ & $\begin{array}{l}\text { Corrected \% } \\
\text { mortality }\end{array}$ & $\begin{array}{l}\text { Conc. } \\
\text { (ppm) }\end{array}$ & $\begin{array}{l}\text { Corrected \% } \\
\text { mortality }\end{array}$ \\
\hline 100 & 89.28 & 1000 & 84.48 & 100 & 91.07 & 100 & 86.20 & 1000 & 82.45 \\
\hline 50 & 82.14 & 500 & 72.41 & 50 & 78.57 & 50 & 72.41 & 500 & 71.92 \\
\hline 10 & 67.85 & 100 & 60.34 & 10 & 64.28 & 10 & 56.89 & 100 & 59.64 \\
\hline 5 & 55.35 & 50 & 46.55 & 5 & 51.78 & 5 & 41.37 & 10 & 45.61 \\
\hline 2.5 & 26.78 & 10 & 24.13 & 1 & 32.14 & 2.5 & 32.75 & 5 & 29.82 \\
\hline 1.25 & 17.85 & 5 & 13.79 & 0.1 & 16.07 & 0.25 & 18.96 & 1 & 14.03 \\
\hline
\end{tabular}

Data are means of three replications.

Table.6 Relative toxicity of insecticides based on $\mathrm{LC}_{50}$ on Lipaphis erysimi by leaf dip method

\begin{tabular}{|c|c|c|c|c|c|c|c|c|c|c|c|c|}
\hline \multirow[t]{3}{*}{ Insecticide } & \multirow{2}{*}{\multicolumn{2}{|c|}{ Heterogeneity }} & \multirow{3}{*}{$\begin{array}{l}\text { Regression } \\
\text { Equation }\end{array}$} & \multirow{3}{*}{$\begin{array}{l}\mathrm{LC}_{50} \\
(\mathrm{ppm})\end{array}$} & \multicolumn{2}{|c|}{ Fiducial limits } & \multirow{3}{*}{$\begin{array}{l}\text { Slope } \pm \text { SE } \\
\text { (b) }\end{array}$} & \multirow{3}{*}{$\begin{array}{l}\text { Relative } \\
\text { Toxicity }\end{array}$} & \multirow{3}{*}{$\begin{array}{l}\text { Order of } \\
\text { Toxicity }\end{array}$} & \multirow{3}{*}{$\begin{array}{l}\mathrm{LC}_{90} \\
(\mathrm{ppm})\end{array}$} & \multicolumn{2}{|c|}{ Fiducial limits } \\
\hline & & & & & Lower & Upper & & & & & Lower & Upper \\
\hline & $\chi^{2}$ & d.f & & & & & & & & & & \\
\hline $\begin{array}{l}\text { Methyl-o- } \\
\text { demeton }\end{array}$ & 6.23 & 4 & $\mathrm{Y}=0.724+1.131 \mathrm{X}$ & 6.034 & 4.513 & 8.069 & $1.131 \pm 0.118$ & 11.18 & 2 & 81.989 & 61.315 & 109.634 \\
\hline Spinosad & 5.80 & 4 & $Y=0.950+1.022 X$ & 9.142 & 6.678 & 12.515 & $1.022 \pm 1.112$ & 7.38 & 4 & 163.896 & 119.725 & 224.363 \\
\hline Acetamiprid & 4.20 & 4 & $Y=0.892+1.078 X$ & 6.487 & 4.784 & 8.796 & $1.078 \pm 0.117$ & 10.40 & 3 & 100.296 & 73.965 & 135.999 \\
\hline Chlorfenapyr & 2.79 & 4 & $Y=2.363+0.706 X$ & 5.429 & 3.463 & 8.513 & $0.706 \pm 0.088$ & 12.43 & 1 & 354.508 & 226.094 & 555.857 \\
\hline Fipronil & 2.30 & 4 & $Y=1.207+0.785 X$ & 67.505 & 44.801 & 101.715 & $0.785 \pm 0.090$ & 1 & 5 & 2891.234 & 1918.816 & 4356.455 \\
\hline
\end{tabular}


Earlier, Rawat et al., (2013) also reported that chlorfenapyr (12.98 ppm), was the most toxic insecticide against green peach aphid, $M$. persicae by leaf dip method followed by thiamethoxam (48.75 ppm), spiromesifen (87.10 ppm) and oxydemeton methyl (338.02 ppm). Studies of Nidhi et al., (2013) found that chlorfenapyr was most effective (12.98 ppm) insecticide against green peach aphid, M. persicae followed by thiamethoxam (48.75 ppm), spiromesifen (87.10 ppm). The $\mathrm{LC}_{90}$ value of the insecticides viz., methyl-odemeton, spinosad, acetamiprid, chlorfenapyr and fipronil were 64.583, 1390.023, 77.070, 166.889 and $2936.680 \mathrm{ppm}$, respectively in direct spray method. Whereas in leaf dip method the $\mathrm{LC}_{90}$ values were $81.989 \mathrm{ppm}$, 163.896, 100.296, 354.508 and 2891.234 ppm, respectively.

Based on the $\mathrm{LC}_{50}$ values, acetamiprid was relatively more toxic insecticide against mustard aphid in direct spray method, whereas, chlorfenapyr was most toxic in leaf dip method. However, methyl-o-demeton was the second most toxic insecticide against aphids in both direct spray and leaf dip methods. Though acetamiprid was relatively most toxic to aphids in direct spray method but it was the third best insecticide in leaf dip method. Similarly, chlorfenapyr was the third best insecticide against aphids when it was directly sprayed. Fipronil was existed in moderate group of toxicity. Spinosad was the least effective insecticide in direct spray method. With respect to $\mathrm{LC}_{50}$ values the order of relative toxicity of insecticides in direct spray method was acetamiprid (11.89) > methyl-o-demeton (11.61)> chlorfenapyr (9.97) > fipronil (3.66) and spinosad (1.0), but in leaf dip method order was changed perceptibly. The relatively low $\mathrm{LC}_{50}$ values of acetamiprid, chlorfenapyr and methyl-odemeton in direct spray method as compared to leaf dip method indicated more bioefficacy of these as direct spray. On the contrary, low
$\mathrm{LC}_{50}$ values of spinosad and chlorfenapyr in leaf dip method indicated better residual effectiveness as compared to direct spray.

It is evident that the neonicotinoids (acetamiprid) was relatively more effective than the other insecticides against L. erysimi. The $\mathrm{LC}_{50}$ values obtained would serve as yardstick for the selection of insecticides against field strains of L. erysimi in any IPM programme.

\section{References}

Abbott, W. S. 1925. A method of computing the effectiveness of an insecticide. Journal of Economic Entomology, 18: 265-267.

Anonymous. 2016a. Agricultural Statistics at a glance. Directorate of Economics and Statistics, Krishi Bhavan, New Delhi. pp-124.

Anonymous. 2016b. Package of Practices for Rabi Crops. Sher-e-Kashmir University of Agricultural Sciences and Technology of Jammu, Jammu.

Awasthi, N. S., Barkhade, U. P., Patil, S. R., and Lande, G. K. 2013. Comparative toxicity of some commonly used insecticides to cotton aphid and their safety to predatory coccinellids. The Bioscan, 8(3): 1007-1010.

Devi, N., Dogra, I., and Raj, D. 2003. Relative toxicity of some recommended insecticides to aphid parasitoid, Diaeretiella rape (Hymenoptera: Braconidae). Journal of Entomological Research, 27(4):335-339.

Dhawan, A., K, Saini, S., Singh, K. and Aneja, A. 2009. Persistence and residual toxicity of some insecticides against Phenacoccus solenopsis on cotton (Gossypium spp). Indian Journal of Agricultural Sciences, 79 (3): 203-6.

Kapila, S. R. S. S., Premi, O. P., Kandpal, B. K., and Chauhan, J. S. 2012. Advances 
in agronomic management of Indian mustard (Brassica juncea (L.): An overview. International Journal of Agronomy, 2012:1-14.

Malik, Y. P, Kumar, J., Singh, S. V., Singh, M., and Bisen, R. S. 2003. Influence of crop management inputs on aphid infestation in Indian mustard. Indian Journal of Entomology. 65: 439-493.

Nidhi, R., Rajpal, S., and Sharma, P. L. 2013. Evaluation of some insecticides against the green peach aphid, Myzus persicae (Sulzer) (Hemiptera: Aphididae). Indian Journal of Entomology. 75(2): 113-17.

Pandi, G. G. P., Paul, B., Vivek, S., and Shankar, G. K. 2013. Relative toxicity of insecticides against coccinellid beetle, Cheilomenes sexmaculata (F.). Annals of Plant Protection Sciences. 21(1): 17-20.

Powar, H. H., Bagde A. S., and Pashte, V.V. 2015. Relative toxicity of selected insecticides to Aphis gossypii (Glover) of some districts of Maharashtra. Trends in Biosciences. 8(16):4131-4134.

Raboudi, F., Moussa, A. B., Makni, H., Marrakchi, M., and Makni, M. 2002. Serological detection of plant viruses in their aphid vectors and host plants in Tunisia. EPPO Bulletin, 32:495-498.

Rana, Z. A., Shahzad, M. A., Malik, N. A., and Saleem, A. 2007. Efficacy of different insecticides and dc-tron plus against mustard aphid, Lipaphis erysimi (Kalt.). Journal of Agricultural Research. 45: 221-224.

Rawat, N., Singh, R., and Sharma, P. L. 2013. Evalution of some insecticides against the green peach aphid, Myzus persicae (Sulzer). Indian Journal of Entomology.75 (2):113-117.

Sharma, N., Jacob, P. S., and Saravanan, L. 2006. Relative toxicity of certain insecticides against mustard aphid, Lipaphis erysimi (Kalt.). The Allahabad Farmer, 11 (1): 51-56.

Singh, B., Singh, R., Mahal, M. S. and Brar, H. S. 1983. Assessment of losses in yield of Brassica juncea by Lipaphis erysimi (Kalt.), influence of varying levels of aphid population. Indian Journal of Ecology. 10: 97-105.

Singh, S. V, Kumar, J., Malik, Y. P., and Bisen, R. S. 2000. Determination of economic status of Lipaphis erysimi (Kalt.) on mustard cultivars. Indian Journal of Entomology 62: 196-202.

\section{How to cite this article:}

Ramana, N., R.S. Bandral and Zahid Abass wazir. 2018. Relative Toxicity of Some Newer Insecticides against Mustard aphid, Lipaphis erysimi (Kalt.) on Gobhi sarson. Int.J.Curr.Microbiol.App.Sci. 7(11): 481-489. doi: https://doi.org/10.20546/ijcmas.2018.711.057 